\title{
Resenha de "Simpatia pelo demônio"
}

Review "Sympathy for the devil"

\section{Donizeth Aparecido dos Santos}

Faculdade de Telêmaco Borba - FATEB - Telêmaco Borba - Paraná - Brasil

\section{Introdução}

Simpatia pelo demônio, de Bernardo Carvalho, lançado em 2016 pela Companhia das Letras, é um romance que trata da violência das relações humanas, tanto no plano individual, a violência física e psicológica não nomeada e nem sempre percebida, quanto no plano coletivo, a violência física nomeada dos conflitos entre diferentes grupos humanos, um mal que o ser humano, mesmo com todo o avanço tecnológico e das leis dos direitos humanos, ainda não conseguiu eliminar. Mas, sobretudo, é um romance sobre o amor, da violência que pode estar embutida na relação amorosa, do quão ela pode ser destrutiva e, principalmente, traz um exemplo do modo que não se deve amar.

O protagonista é Rato, um brasileiro com formação em Direito que escreve uma tese nos Estados Unidos sobre a violência em zonas de conflito armado. A tese se torna famosa e uma referência obrigatória sobre o tema nos cursos de ciências humanas. Por conta dela e também do seu trabalho numa agência humanitária de Nova York, ele atua como observador em zonas de conflito e é requisitado para dar palestras sobre a violência em seminários e congressos no mundo todo.

Recém-entrado na meia idade, Rato é casado com uma acadêmica com que tem uma filha e pode ser considerado um homem realizado na vida pessoal e

profissional, até que um encontro inesperado num teatro em Berlim vai levá-lo ao fundo do poço com a perda de tudo que havia conquistado até então: amorpróprio, autoestima, família e respeitabilidade profissional. $O$ elemento desencadeador de tal situação é a paixão destrutiva por um neurocientista mexicano chamado por Rato de Chihuahua, que ele conhece na antessala do teatro em Berlim e partir daí a sua vida se transforma num verdadeiro caos, pois 0 amante é um predador, cuja satisfação é a destruição de todo mundo que se apaixona por ele: "Sua missão era uma só: destruir o ego dos outros, enquanto promovia o seu. Quanto mais egos aniquilados, melhor" (CARVALHO, 2016, p.184).

A paixão à primeira vista pelo Chihuahua é causada, em parte, pela crise da meia idade de Rato, período em que tudo passou a ser urgente para ele e o amor do mexicano representava uma espécie de volta à adolescência: “... o Rato sentiu por ele uma atração que já não podia sentir por mais ninguém e ainda menos pela mulher, uma atração que havia perdido na juventude e que o fazia acreditar de novo no amor." (CARVALHO, 2016, p.94-95), mas também pelo caráter imaturo e vulnerável que o Rato tinha em questões amorosas, que o fez se jogar de cabeça nessa paixão e o transformou na presa ideal para 0 Chihuahua. Dessa forma, o homem que era corajoso e forte nas situações de violência extrema dos conflitos armados dos quais participava como mediador, era frágil na vida pessoal: "A valentia da guerra encobria uma vulnerabilidade íntima e irremediavelmente imatura: Corria menos riscos na guerra do que na vida amorosa" (CARVALHO, 2016, p.80).

Essa dicotomia que o Rato apresenta, forte na guerra e frágil no amor, se reflete também na relação 
amorosa com o Chihuahua. A passividade do mexicano no ato sexual escondia a plena dominação e controle que ele tinha sobre Rato, aparentemente o elemento ativo na relação: "Ele manipulava descaradamente o Rato, que já não estava em condições de reagir a coisa alguma. Estava um trapo, só ele mesmo não sabia" (CARVALHO, 2016, p.115).

O romance é narrado em terceira pessoa por um narrador que está colado ao Rato, ou seja, um narrador que possui uma "visão com", conforme a terminologia de Pouillon (1974). Desse modo, é a partir do Rato que vemos os outros, é a perspectiva dele que conduz a narrativa. A narrativa, por sua vez, não é linear. Há um entrelaçamento entre vários níveis temporais, intercalando-se passado e presente por meio de anacronias narrativas: analepses, que evocam acontecimentos anteriores, e prolepses que evocam de antemão acontecimentos posteriores, conforme a teoria narrativa de Genette (1976). No início do primeiro capítulo do romance, intitulado "A agência humanitária", Rato está sendo incumbido pelo diretor da agência de uma missão dificílima, quase suicida: ir ao Oriente Médio pagar o resgate de um prisioneiro de um dos grupos em conflito na região. A missão, que vai contra o regulamento da agência, só é dada ao Rato e aceita por ele pelo fato de que naquela altura dos acontecimentos a sua vida já tinha descambado e ele praticamente não tinha mais nada a perder, além da própria vida. A partir da metade do primeiro capítulo e nos capítulos seguintes (Perdeu, $O$ palhaço, O sacrifício perpétuo), através de avanços e recuos temporais realizados por meio das anacronias narrativas, todo o drama pessoal de Rato é revelado em seus pormenores. No capítulo final, "O resgate", a narrativa volta a abordar a missão dada ao Rato, apresentando o desfecho dela.

Dessa forma, o primeiro e o último capítulo, focados na missão do Rato e narrados num mesmo tempo narrativo, funcionam na estrutura narrativa do romance como uma espécie de moldura ${ }^{1}$, que abre e fecha a obra e envolve em seu interior a narrativa do

${ }^{1}$ Utilizo o termo "moldura" da mesma forma utilizada por Regina Zilberman no ensaio "História, mito, literatura" sobre a estrutura narrativa de $O$ tempo e o vento de Erico drama pessoal do protagonista. Nesse sentido, levando-se em conta que esses dois capítulos abordam a violência num plano coletivo, a violência física dos conflitos entre facções no Oriente Médio, e os três capítulos intercalados abordam a violência psicológica sofrida pelo protagonista no relacionamento amoroso com o Chihuahua, essa moldura também pode ser relacionada, num plano analógico, ao fato de que toda violência coletiva é permeada pela violência individual, física ou psicológica. Ou, conforme observa Losnak (2016, p.3) em sua análise do romance, "a violência coletiva (...) nasce de um desejo individual. No processo de realização de um desejo de amor, o ser humano pode utilizar as ferramentas mais abomináveis e violentas. O mesmo processo poderia ser estendido aos desejos ideológicos, econômicos e políticos dos povos e nações".

Resende (2008, p.82), numa análise dos livros de Bernardo Carvalho anteriores a 2008, ao falar sobre Mongólia, observa que "nesse romance, como em toda obra de Carvalho, os grandes temas são os que deram origem às tragédias clássicas, da Antiguidade a Shakespeare". Em Simpatia pelo demônio, Bernardo Carvalho não foge à escrita observada por Beatriz Rezende de procurar os seus temas nas tragédias clássicas, e traz à cena em seu romance uma peça clássica do século XIX, Ivánov, escrita pelo russo Anton Tchekhov em 1887. A alusão à peça russa um pouco depois da metade do primeiro capítulo serve como introdução ao drama humano do protagonista que seria narrado nas páginas seguintes.

Numa das inúmeras analepses do romance, Rato recorda a encenação da peça feita por um grupo de teatro de um ex-colega da faculdade, que ele tinha assistido junto com a sua mulher, no Rio de Janeiro, no ano em que a conhecera. A descrição do caráter de Ivánov que surge nas discussões do casal sobre a peça nos dá uma visão antecipada do perfil do Chihuahua. Na visão do casal, o vilão/protagonista de Tchekhov “... é o típico sedutor. Não ama ninguém

Verissimo, publicado em $O$ tempo e o vento: história, invenção e metamorfose (2004), de autoria de Maria da Glória Bordini e Regina Zilberman. 
além de si mesmo" (CARVALHO, 2016, p. 38), um monstro, cuja natureza ele próprio não podia contrariar.

Dessa forma, Bernardo Carvalho já nos aponta o caráter do tipo de pessoa com a qual Rato iria se envolver. "Há milhares de Ivánov... Ivánov é o homem mais normal do mundo... O Rato nunca tinha pensado que houvesse milhares de Ivanov no mundo, mas, como se o buscasse inconscientemente desde então, terminou por encontrar pelo menos um" (CARVALHO, 2016, p. 38).

Bernardo Carvalho também recorre a outros elementos intertextuais, que funcionam na estrutura narrativa como uma espécie de metaficção, pois, por analogia, explicam os perfis dos personagens ou determinadas situações vivenciadas por eles. Além da peça teatral que introduz o drama de Rato, o autor também lança mão das artes plásticas. Primeiro com a analogia entre o quadro "Sansão e Dalila", de Max Liebermann, e a situação de penúria a que Rato tinha sucumbido depois do envolvimento com o Chihuahua: "É uma cena terrível, que representa o herói conduzido à derrocada pelo desejo. O indivíduo entende a um só tempo por que a mulher o amou - e que o amor não era nada. É como acordar no inferno" (CARVALHO, 2016, p. 72). Ou, ainda, a análise feita pelo Rato do "São Cristóvão", de Bosch, da representação de um homem que se esforçava para enforcar um urso num galho de árvore, encaminha a narrativa para o seu desfecho. Não por acaso, essa imagem está na capa do livro. A revelação que lhe vem dessa análise, "que os pecados do mundo eram mais pesados que um urso" (CARVALHO, 2016, p.214), é que o leva a aceitar a missão, suicida ou quase impossível, que é dada pelo diretor da agência. Com isso, Rato esperava se livrar não apenas do Chihuahua, mas também do peso do mundo: "Sentia que, como São Cristóvão, já tinha lidado com o diabo, mas não queria carregar mais ninguém nos ombros" (CARVALHO, 2016, p.214).

Outra estratégia narrativa utilizada por Bernardo Carvalho é a estrutura de fábula dada ao romance, nomeando os personagens principais com nome de animais, embora não haja nenhuma moral no fim da história. Chihuahua é o nome do estado mexicano de origem do personagem que leva a alcunha, mas também é o nome de uma raça mexicana de pequenos e encantadores cães, tidos como delicados, afetuosos e possessivos, uma descrição que se aproxima muito da imagem que o Rato tinha do amante no início do relacionamento, um homem de pequena estatura que era "um ser extraordinário e único" (CARVALHO, 2016, p.190). Já o Rato, como sabemos, é o animal utilizado como cobaia em experiências de laboratório e uma presa de vários predadores. No romance, Rato é uma presa fácil, é manipulado e maltratado o tempo todo pelo Chihuahua, que também gostava de ser chamado na cama de "raposinha", um animal predador e traiçoeiro.

Dessa forma, Bernardo Carvalho constrói uma narrativa intertextual em que qualquer elemento inserido no texto tem uma razão de ser, algo para explicar ou ser comparado, como um elemento que tem uma função metaficcional, seja na utilização da estrutura de fábula com a escolha de nomes de animais para os personagens ou no diálogo que estabelece com o teatro, as artes plásticas e obras literárias e ensaísticas, aos quais faz referências explícitas no romance. Em relação ao nome do livro, a escolha também não é gratuita: no último encontro entre Rato e Chihuahua, enquanto faziam amor, Rato viu a encarnação do demônio no "homem que ele amou, por quem seria capaz de largar tudo".

Mais que um livro sobre a violência, Simpatia pelo demônio é um romance que desvela o mal e a violência que podem estar embutidos nas relações amorosas e do tanto que elas podem ser destrutivas para algumas pessoas que não saibam lidar com elas. Ou seja, aquilo que era somente para trazer o bem, a felicidade, pode trazer também, muitas vezes, o mal, a destruição.

\section{Referências}

BORDINI, Maria da Glória; Zilberman, Regina, O tempo e o vento: história, invenção e metamorfose. Porto Alegre: EDIPUCRS, 2004.

CARVALHO, Bernardo. Simpatia pelo demônio. São Paulo: Companhia das Letras, 2016. 
GENETTE, Gérard. Discurso da narrativa. Trad. Fernando Cabral Martins. Lisboa: Veja, 1976.

LOSNAK, Marcos. O terror do amor. Folha de Londrina, Londrina, 21 set. 2016 . Folha 2, p. 3.

POUILLON, Jean. O tempo no romance. São Paulo: Cultrix, EdUSP, 1974.

RESENDE, Beatriz. Contemporâneos: expressões da literatura brasileira do século XXI. Rio de Janeiro: Casa da Palavra: Biblioteca Nacional, 2008.

DOS SANTOS, Donizeth Aparecido. Resenha de "Simpatia pelo demônio". Signo, Santa Cruz do Sul, v. 45, n. 84 p. 113-116, nov. ISSN 1982-2014. Disponível em: <https://online.unisc.br/seer/index.php/signo/article/view/13181>. doi:https://doi.org/10.17058/signo.v45i84.13181. 